\title{
Management Changes and Employees' Attitudes in Transcorp Hotel, Calabar, Cross River State, Nigeria
}

\author{
Lebo, Monica Peter Alfred JM Edema \\ Department of Business Management, University of Calabar, Calabar
}

\begin{abstract}
This study investigated the relationship between management changes and employees' attitudes in Transcorp Hotel, Calabar, Cross River State, Nigeria. The population of the study was 1,328 employees out of which a sample of 307 was drawn using the simple random sampling method and Taro Yamane formula. Two instruments for data collection were: Management Changes Rating Scale and Employees' Attitudes Rating Scale. The Hypothesis was tested using simple linear regression at $\mathrm{p}<0.05$ with the aid of SPSS. The study found out that there is a significant relationship between management changes and employees' attitudes in the hotel. Thus, the study recommended that the management of Transcorp Hotels, Calabar should reappraise the management changes implemented to ensure the cultivation of positive attitudes among employees.
\end{abstract}

Keywords: Management Changes, Employees Attitudes, Transcorp Hotel Nigeria

DOI: $10.7176 / \mathrm{EJBM} / 11-33-06$

Publication date: November $30^{\text {th }} 2019$

\section{Introduction}

The past ten years have witnessed phenomenal changes in the tourism sector that reflect worldwide trends in reforms that have affected the Nigerian tourism industry. These changes include readjustment in organizational culture to accommodate global clients' and customers' requirements, new management structures and processes in order to achieve performance targets, accurate costing of services to clients' and customers' total satisfaction. These changes are particularly noticed in service delivery such as provision of internet-based services and a greater demand for client and customer security. These demands have created the need for management changes in order to meet the demands of global tourism markets for Transcorp Hotel services. The task of maintaining employees' positive attitudes in the midst of these changes has become a major issue to the management of Transcorp Hotel especially because of the takeover of the former Metropolitan Hotel, Calabar and the wider and more efficient services required. Therefore, employees' attitude towards management changes has been questioned because of what may occur in the course of the changes in terms of retaining, retraining or laying employees off (Sikh \& Gls, 2011), operational procedures (Fagbihi \& Allameh, 2012) and career longevity (Farouk, 2014). Employees' attitudes are certain regularities of an individual's feelings, thoughts and predispositions to act toward some aspects of his environment (Eby, Adams, Russell \& Gaby, 2000). It reflects a person's intention to feel, think or even behave in a positive or negative manner towards the object in question. Attitude towards change involves a person's cognition about change, affective reactions to change, level of commitment and behavioral tendency towards change. Fagbihi \& Allameh (2012) argue that attitude towards organizational change is employees' overall positive or negative judgment of the management initiative implemented by their organization. It is a person's internal state of mind that influences his choice of action or response tendency towards the change. It is interpreted as a personality dimension coming to the fore in the individual's behavior towards others on certain situations (Anghelache \& Corina, 2011).

The acceptance and effectiveness of organizational change depends on employees' deep commitment to organizational culture, structure and supportive leadership style. Employees' acceptance or rejection of management change depends on organizational capability to implement effective change as enunciated by Theory O (Beer \& Nohria, 2000).

Consequently, it has become necessary to investigate employees' attitudes toward management changes in Transcorp Hotel, Calabar, Cross River State, Nigeria. Therefore, the objective of this study is to ascertain the relationship between employees' attitudes and commitment in Transcorp Hotel, Calabar Cross River State. Consequently, the research question is: What is the relationship between employees' attitudes and commitment in Transcorp Hotel, Calabar? Based on this research question, the single null hypothesis $-\mathrm{H}_{\mathrm{o}}$ is: There is no significant relationship between employees' attitudes and commitment in Transcorp Hotel, Calabar. Although this study is limited to management changes and employees' attitudes in Transcorp Hotel, Calabar, the result can be generalized and used in other hotels, in and outside Calabar, which makes its contribution significant to both hotels managers and employees.

This paper is organized as follows: the introduction discusses a brief background to the study capturing the theoretical and empirical contributions to the subject matter, objective, question, and hypothesis, limitations and significance. The second segment of the paper takes on review of relevant literature. The third part, deals with empirical reviews. The forth, fifth, and sixth sections, present respectively, the methodology and results; finding 
and discussions; and finally, recommendation.

\section{Theoretical Framework}

This study is anchored on Theory O propounded by Beer \& Nohria (2000). Theory O is a change theory based on organizational capability. That is, development of organization's human capability to implement change strategy and learn from past and present experiences in the global market. The acceptance and effectiveness of organizational change depends on employees' high commitment to organizational culture, structure and supportive leadership style. The employees' acceptance or rejection of management change depends on organizational capability to implement effective change. Theory $\mathrm{O}$ is relevant in this study because through organizational capability, employees' positive attitude can be maintained towards change in structure, culture and leadership style that enhance organizational performance. The application of Theory $\mathrm{O}$ ensures the confidence of employees to achieve individual company's goals and objectives and the corporate success of companies in the industry.

\section{Literature Review}

No organization is immune to change in order to meet local and global needs. As globalization continues to confront the appropriateness of modern organizational strategies, processes, culture and structures, organizations are expected to steadily grapple with the costs and benefits associated with change (Bellow, 2007; Durnaz, 2007). Thus, there are three basic variables of organizational change namely, organizational culture, organizational structure and leadership.

Organizational culture is a set of values, beliefs, standards, assumptions and thoughts accepted by all members of the organization (Mansoor \& Tayib, 2010). Culture is the peoples' way of life which reflects the accepted norms and standards which both management and employees can not deviate from while working in the organization. As change is being introduced, employees are often conscious whether such change is in consonance with the organization's culture. This would go a long way to determine the level of acceptance or rejection of the change which may affect its effectiveness. Organizational culture guides the attitudes and behaviors of members and affects what they do.

Organizational structure defines the ways jobs are shared and allocated to individual employees or groups of employees which reflects the authority and responsibility to enhance the effectiveness of change process. Organization structure determines the job roles and expected results required from individual employees handling such task responsibility. Organizational change often affects individual task responsibility which invariably leads to layoff if they are not aware and prepare for the change process. This is why many employees reject change for fear of redundancy in the organization.

The leadership style exhibit by the managers in the organization affects the attitudes of employees toward accepting or rejecting change. Participative management style often influences employees to accept any change that may occur in the organization. Leadership style is the pivot on which change revolves as the effectiveness of change depends on the type of leadership style prevailing in the organization. Individual employee who has invested in the organization will strike to ensure change succeeds to enhance his return on investment. Even the costs of leaving the organization to be high, such employee will display positive attitude and commitment in order to fit in the organization.

Fagbihi \& Allameh (2012) argue that leadership style determines to a large extent the economic success of an organization and employee commitment to that effect. Leadership style is a series of managerial attitudes, behaviors, characteristics and skills based on individual and organizational values, interest and reliability of employees in different situation (Menguc \& Auh, 2010). Normative commitment is a feeling of obligation to continue employment with the organization. Employees with high level of normative commitment feel that they ought to remain with the organization to facilitate change process in order to enhance organizational effectiveness. In order to implement organizational change effectively, leaders must influence employees to display high level of normative commitment and this is done not only by communicating the change but through actions that motivate employees to see the change process is a necessary requirement for organizational effectiveness and competitive advantage in the global dynamic business environment (Abdullah, Alzaidiyeen \& Aldarabah, 2009).

Employee's readiness to accept change depends on the type of organization's leaders. Appropriate leadership style (participative leadership style) influences employee's attitude toward employee commitment to change. Employees' attitudes are certain regularities of an individual's feelings, thoughts and predispositions to act toward some aspects of his environment (Eby, Adams, Russell \& Gaby, 2000). It reflects a person's intention to feel, think or even behave in a positive or negative manner towards the object in question. Attitude towards change involves a person's cognition about change, affective reactions to change, level of commitment and behavioral tendency towards change. Fagbihi \& Allameh (2012) argue that attitude towards organizational change is employees' overall positive or negative judgment of the management initiative implemented by their organization. It is a person's internal state of mind that influences his choice of action or response tendency towards the change. It is interpreted as a personality dimension coming to the fore in the individual's behavior towards others on certain 
situations (Anghelache \& Corina, 2011).

Besides, attitude is a hypothetical construct that represents an individual's likes or dislikes for any behavior. It is a mental state of readiness, organized through experience, exerting a directive or dynamic influence on the individual's response to all objects and situations to which it is related (Ahmad, Ahmad \& Syah, 2010). In a simpler form, attitude is a mindset or tendency to act in a particular way due to both experience and temperament. Employee attitudes to work can be measured on the level of employee ambition to commitment to organizational goals, level of dependability to achieve the stated goal and objectives, level of teamwork or cooperating and achieving both the individual and general corporate goals and level of self-control employees have toward achieving organizational goals.

\subsection{Empirical Review}

A study on how strategic management change affects employees' commitment and type of organizational culture was conducted by Persson (2014). The purpose of the study was to determine the extent to which management change influenced employees' commitment, organizational structure and culture. The study employed descriptive survey design. Data collected using questionnaire was analyzed with regression. The finding showed that there was a positive correlation between organizational culture, employees' commitment and management change. The study concluded that employees' commitment increased due to management change. The study recommended that when conducting organizational changes, organizations should endeavor to increase their employees' commitment through culture.

Visagie \& Steyn (2011) conducted a study on organizational commitment and responses to planned management change in Cape Peninsula. The objective of the study was to ascertain the extent of employees' commitment and attitudes towards management change. Data were collected from respondents through electronic survey and analyzed using mean, standard deviation and coefficient of correlation. Findings revealed that employees' commitment and attitudes were positively associated with management change. The study concluded that organizational change interventions and activities such as training and communication should be related to employees' commitment and attitudes towards organizational change. The study recommended that organizational change practitioners should promote employees' commitment and attitudes towards management change.

A study on employee attitudes and job satisfaction in Florida was conducted by Saari \& Judge (2004). The aim of the study was to determine the effect of employee attitude toward organizational culture on commitment and job satisfaction. The employed a theoretical approach and secondary data mainly through the reviewed literature were used. Findings showed that employees' attitude to organizational culture affect their affective commitment and job satisfaction. The study concluded that organizational culture predicts the attitude of employees toward commitment and job satisfaction and for change process to be effective, the employees' attitude must be in line with the culture which may influence their commitment and job satisfaction and success of change process. The study recommended that employee attitudes should be reshape through acceptable culture to enhance organizational commitment toward successful change implementation.

Shah \& Irani (2010) conducted a study on examining employee attitudes and behavior towards organizational change using superior and peer relations in Pakistan. The purpose of the study was to determine superiors and peers relations along with personal, characteristics to know employee attitudes and behavior towards organizational change in Pakistani organization. The study was a descriptive survey design. Structured questionnaire was distributed to 100 respondents randomly selected for the study. The data collected were analyzed Pearson Product Moment Correlation, multiple regression and multi analysis of variance (MANOVA) to establish the relationship between the variables. The findings revealed that there is a positive significant relationship between employee commitment and change through the attitude of supervisor and peer support. The study concluded that employees could develop their positive attitudes and behaviours toward change on the basis of supervisor and peer relation through higher commitment. The study recommended that these factors should be considered within policy and strategy to promotion employee openness and readiness for organizational change.

Wang (2007) conducted a study on organizational culture, organizational commitment and attitude towards organizational reform in Chana. The aim of the study was to determine the extent to which employee attitude toward organizational reform in relation to school culture affect organizational commitment. The study employed descriptive survey design. Data were generated from structured questionnaire administered to respondents. Thus, the data collected were analyzed using one-way ANOVA and multiple regression analysis to determine the distinction and situation in organizational culture, commitment and attitude toward organizational reform among different employees. The results showed that there is a positive significant correlation among organizational culture, organizational commitment and attitude of staff toward organizational change. Also, there is significant influence of organizational commitment by staff and organizational culture on the attitude of staff toward organization change process. The study concluded that organizational commitment and culture would affect employees' supportive attitude toward organizational change in a positive relation. The study recommended that organizations that want to successfully implement comprehensive change system should improve employees' 
commitment, increase their recognition and feel to belonging and display positive attitude towards change process.

\section{Methodology}

A correlation design was adopted for this study so as to determine the linear relationships between the variables under investigation. The population of the study constituted 1,328 employees of Transcorp. A sample of 307 employees was identified for this study. Simple random sampling method was used to identify the sample. This method was used because all employees exhibited the same work attitudes under the management changes implemented. The instruments used for data collection were: Employees' Attitudes Rating Scale (EARS) figure 1, and Management Changes Rating Scale (MCRS) figure 2. Data collected with the instruments were analyzed using Simple linear regression with the aids of SPSS to answer the research question so as to determine the relationship between the variables of the study as shown in Table 1.

\subsection{Hypothesis}

There is no significant relationship between employees' attitudes and management changes.

Table 1. Least square regression results for employees' attitude

\begin{tabular}{lllll}
\hline Variables & Beta & Standard errors & T & Sig \\
\hline (Constant) & 5.623 & .956 & 5.882 & .000 \\
Management change & .695 & .049 & 14.039 & .000 \\
$\mathrm{R}$ & .627 & & & \\
$\mathrm{R}^{2}$ & .393 & & & \\
Adjusted R & .391 & & & \\
F-valve & 197.093 & & & \\
Sig & .000 & & & \\
\hline
\end{tabular}

a predictor: Management changes

b dependent variable: Employees' attitude

Source: Researchers computation from SPSS output

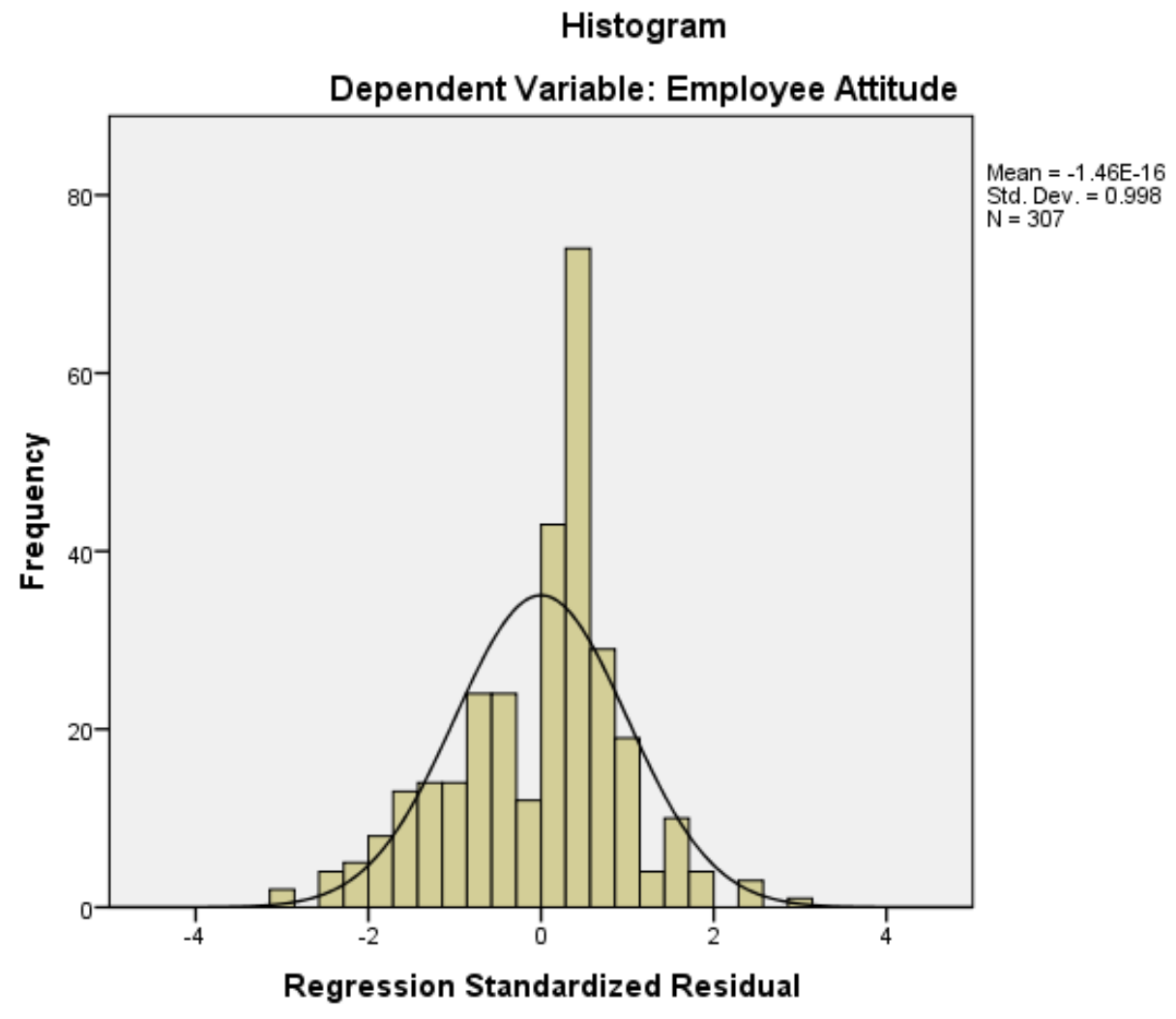

Figure1. Employees’ Attitudes Rating Scale 


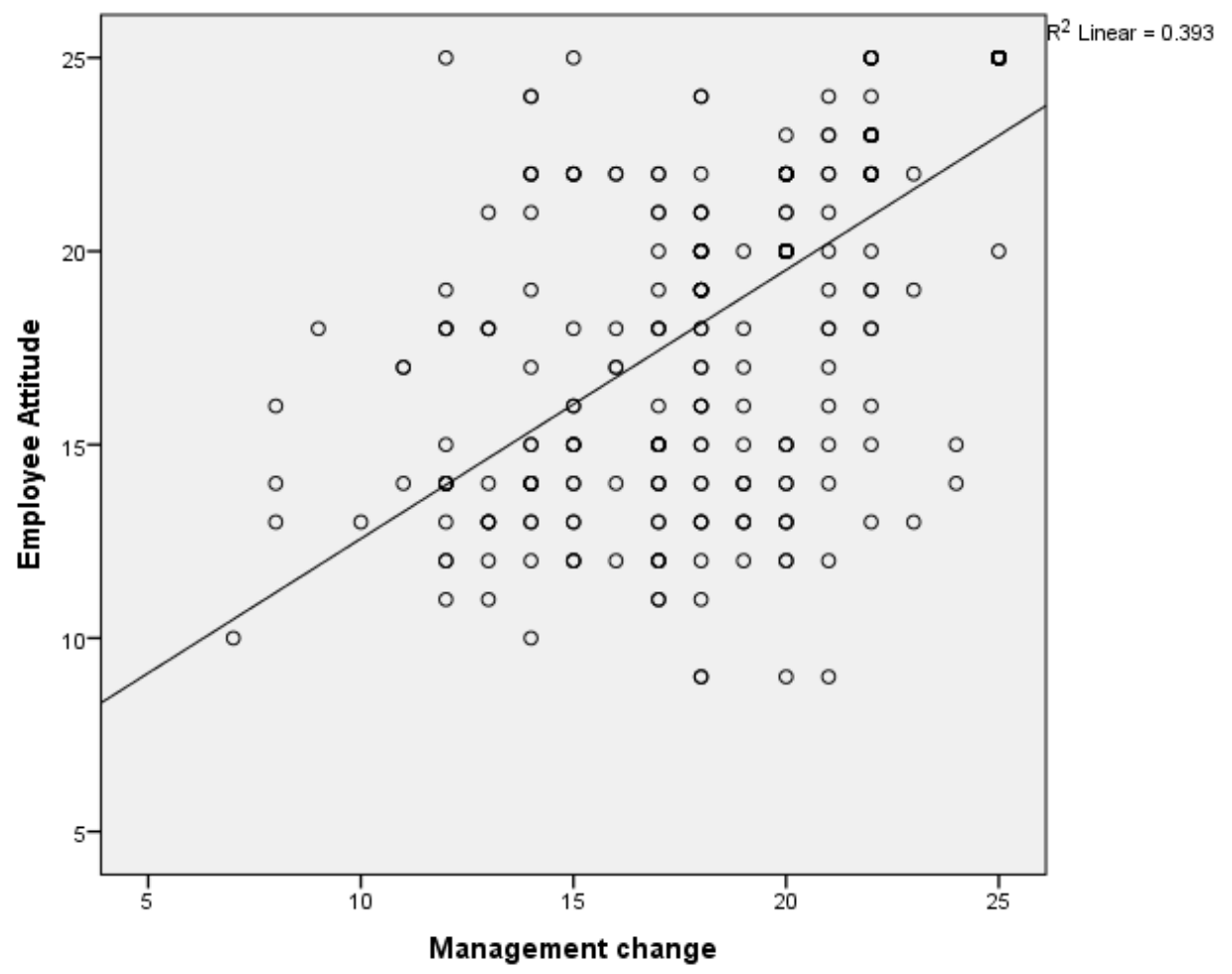

Figure 2. Management Changes Rating Scale

The results of the analysis are presented in table 1 . The R-value of .627 shows the level of correlation between employees' attitude and management change. The adjusted $\mathrm{R}^{2}$-value of .391 shows that 39.1 percent of the variance in employees' attitudes is explained by management change. The model significant of equation is shown thus: $\mathrm{F}(1,305)=197.093, \mathrm{p}<.005$ indicating that, the overall prediction of the independent variable to the dependent variable is statistically significant, therefore, the regression model is a good fit for the data and provides, sufficient evidence to conclude that the management change is related with or enhances employees' in the firm. The equation of the line for using management change to predict employees' is $\mathrm{Y}=.695 \mathrm{x}+5.623$ which is statistically significant with $\mathrm{t}=14.039$ and $\mathrm{p}<.005$, where .695 is the slope for the management change and 5.623 is the $y$-intercept.

\section{Findings and Discussion}

The main finding is that there is a significant relationship between management changes and employees' attitudes in Transcorp Hotels, Calabar. This finding corroborates with the conclusion of the study by (Shah \& Irani, 2010) that employees' commitment increased due to management changes. Correspondingly, the finding in the study by (Visagie \& Steyn, 2011) revealed that employees' commitment and attitudes were positively associated with management changes. Implications are that organizational change interventions and activities such as training and communication could be related to employees' commitment and attitudes towards organizational change.

\section{Recommendations}

This study recommends is that the management of Transcorp Hotels, Calabar should reappraise the management changes implemented and ensure the cultivation of positive attitudes among employees; through concerted sensitization of employees to reverse imminent negative attitudes to enable the company deliver efficient and satisfactory services to its customers.

\section{References}

Abdullah, A. G. K; Alzaidiyeen, N. J. \& Aldarabah, I, T. (2009). Workplace Spirituality and Leadership Effectiveness among Educational Managers in Malaysia. European Journal of Social Sciences, 10 (2), 304316.

Ahmad, H; Ahmad, K. \& Syah, I. A. (2010). Relationship between Job Satisfaction, job Performance, Attitude towards Work and Organizational Commitment. European Journal of Social Sciences, 18 (2), 257-267.

Anghelache, V. \& Corina, B. C. (2011). Educational Changes and Teacher's Attitude towards Change. Social and Behavioural Sciences, 33; 593-597.

Beer, M. \& Nohria, N. (2000). Cracking the code of change. Harvard Business Review, 78, 133-41.

Bellow, V. (2007). Psychological Contract Assessment after a Major Organizational Change: The Case of Merger 
and Acquisitions. Employee Relations, 29 (1), 68-85.

Durmaz, H. (2007). Officer Attitudes towards Organizational Change in the Turkish National Police. Unpublished Doctoral Thesis, University of North Texas, Texas.

Eby, L; Adams, D; Russell, J. \& Gaby, S. (2000). Perception of Organizational Readiness for Change: Factors Related to Employee's Reactions to the Implementation of Team-based Selling. Human Relations, 53 (3), 419-428.

Fagbihi, A. \& Allameh, S. M. (2012). Investigating the influence of employee attitudes towards change and leadership style on change readiness by SEM (Case study: Isfahan Municipality); International Journal of Academic Research in Business and Social Sciences; Vol.2 No.1; 215-227.

Farouk, I. (2014). Exploring employee attitude and productivity at Electricity Company of Ghana, Ashanti-East; Unpublished MBA Thesis; Kumasi: Kwame Nkrumah University of Science \& Technology.

Mansoor, M. \& Tayib, M. (2010). An Empirical Examination of Organizational Culture, Job Stress, Job Satisfaction within the Indirect Tax Administration in Malaysia. International Journal of Business and Social Sciences, 1 (1), 81-95.

Menguc, B. \& Auh, S. (2010). Development and Return on Execution of Product Innovation Capabilities: The Role of Organizational Structure. Journal of Industrial Marketing Management, 39 (5), 820-831.

Persson, S. (2004). How Readiness for Strategic Change affects Employee Commitment and Flexibility: Considering Type of Organizational Culture; Masters of Thesis, School of Health Society. International Journal of Business and Economics.

Saari, L. M. \& Judge, A. T. (2004). Employee Attitude and Job Satisfaction. Journal of Human Resource Management, 43 (4), 395-407.

Shah, N. \& Irani, Z. (2010). Examining Employee Attitudes and Behaviours towards Organizational Change using Supervisor and Peer Relations. European Mediterranean and Middle Eastern Conference on Information Systems, April, 12-13, 1-15.

Sikh, G. \& Gls, N. (2011). Analysis of attitudes and behaviours of employees towards organizational change; International Journal of Human Resources Management and Research; Vol.1 Issue 1; 1-13.

Visagic, C. M. \& Steyn, C. (2011). Organizational Commitment and Responses to Planned Organizational Change: An Exploratory Study. Southern African Business Review, 15 (3), 98-121.

Wang, H. C. (2007). Study on Organizational Culture, Organizational Commitment and Attitude toward Organizational Reform: Comprehensive High School as example. The Journal of Human Resource and Adult Learning, 3 (2), 189-198. 